\title{
Nursing practices in vaccination: An integrative review
}

\author{
Luís Gustavo da Silva Fagundes*1, Oleci Pereira Frota ${ }^{2}$, Eliete Maria Silva ${ }^{1}$ \\ ${ }^{1}$ Nursing school, Campinas State University, Campinas, São Paulo, Brazil \\ ${ }^{2}$ Institute of the Integrated Health Institute, Federal University of Mato Grosso do Sul, Mato Grosso do Sul, Brazil
}

Received: November 25, 2017

DOI: $10.5430 /$ jnep.v8n8p128
Accepted: April 2, 2018

Online Published: April 11, 2018

URL: https://doi.org/10.5430/jnep.v8n8p128

\begin{abstract}
In this paper, an integrative literature review was carried out aiming to answer: what is the nursing scientific production about vaccination practice? Research conducted in the Medline, SciELO, Lilacs, BDENF, PubMed, CINAHL and Scopus databases from 2010 to 2017. A sample of 49 papers was obtained. Most of the papers were classified with level VI of evidence. The highest level found was the II, controlled and randomized studies of level III accounted for $10.20 \%$. The papers were grouped by similarity into four thematic categories: vaccine coverage $42.86 \%$, administration of vaccine $28.58 \%$, vaccination education $14.28 \%$ and management/supervision $14.28 \%$. It management/supervision and education about vaccination are highlighted in most papers. The methodology used allowed the analysis and summarization of papers with different approaches. It is evident that vaccination goes far beyond the simple fact of administering an immunobiological, requiring an extensive and complex body of knowledge, with frequent updating of health professionals, especially nurses. Vaccination actions are effective in preventing diseases, and it is important to prioritize such actions in their daily practice. In nursing vaccination practices, nurses should assert their supervisor assignment, contributing to the organization of the service, continuing education of nursing staff, planning strategies to reach the goals of vaccination, evaluating vaccination coverage, working according to the population, through their education and awareness, and contribute with the body of knowledge about vaccination.
\end{abstract}

Key Words: Immunization, Vaccination, Immunization programs, Evaluation of processes, Nursing

\section{INTRODUCTION}

The history of vaccination has been developing over the years, contributing significantly to reducing deaths from infectious diseases. ${ }^{[1]}$ With the evolution of vaccines current days, more than 200 years have passed since the observations of Edward Jenner about the effects of bovine pox to prevent human pox. ${ }^{[2]}$ In the years 1940 , the discovery that the virus could be cultured in vitro in animal cell cultures allowed the development of many vaccines such as against poliomyelitis, measles, mumps, rubella, varicella, hepatitis A and, more recently, rotavirus and influenza. ${ }^{[3]}$

Because of the Millennium Summit in 2000, vaccination is highlighted among the actions of the Millennium Develop- ment Goals, highlighting its role in reducing child mortality. Currently there are national immunization programs in all countries, most of which follow the recommendations of the World Health Organization, avoiding more than 2.5 million child deaths each year due to vaccine-preventable diseases. ${ }^{[4]}$

The role of nursing in public health in the world today is the key member of the interdisciplinary team, contributing significantly to primary care in its goals of promoting and protecting health. Nurses are key components of public health interventions, including, but not limited to, newborn care, health education, immunization and screening clinics, disaster management and emergency preparedness. In this way, it encompasses a unique set of skills needed to plan, im-

*Correspondence: Luís Gustavo da Silva Fagundes; Email: gufagundes@ yahoo.com.br; Address: Nursing School, Campinas State University, Street Tessália Vieira de Camargo, 126-University City, Campinas, São Paulo, Brazil. 
plement and evaluate public health interventions. In the face of an epidemic or pandemic, public health departments and health organizations are urging nurses to develop programs to address the need to protect the population through mass vaccination, education and management. ${ }^{[5]}$

Nurses play a central role in promoting and delivering vaccination programs worldwide. Be active in the organization of public health - in which they are responsible for the management and organization of immunization programs for the general population - or in the vaccination of families: as part of health teams, in general clinical practice or in pediatric settings. In the approach to primary health care by nursing it is evident that the practices of disease prevention and health promotion offer the best path for a healthy population. Vaccination is considered a precaution, a tool that allows nurses to help protect people from serious illness. ${ }^{[6]}$

Vaccination has brought gains to human health. There is an interrelationship that nursing has with the vaccination process, we aim to identify the themes present in the scientific literature on nursing practice in vaccination, to systematize their professional and social contribution in this dynamic and necessary process which has become the current vaccination.

\section{MethodS}

As we looked at this issue, one question emerged: what is the scientific production of nursing about vaccination practice? To answer this question, we follow the following steps: identification of the theme and selection of the hypothesis or question of research, establishment of inclusion/exclusion criteria for studies/sampling, definition of the information to be extracted from the selected studies/categorization of studies, evaluation of the studies included in the sample, interpretation of results and presentation of the review/synthesis of knowledge. ${ }^{[7]}$

Nursing practices should be linked to good evidence in decision-making in their actions. We understand evidencebased nursing as an ongoing process whereby evidence, nursing theory, and professional clinical experience are critically evaluated and considered, together with the patient, to provide the best nursing care to the individual. ${ }^{[8]}$ We performed the classification of the evidence of the selected papers, following recommendations: ${ }^{[9]}$ Level I. Systematic Review or Meta-analysis of all randomized controlled clinical trials or guidelines based on systematic reviews of controlled clinical trials. Level II. Randomized controlled trial of randomized, controlled, and well delineated clinical trial. Level III. Controlled study with randomization, well-designed and controlled study without randomization. Level IV. Casecontrol study or cohort study. Level V. Systematic review

Published by Sciedu Press of qualitative or descriptive studies. Level VI. Qualitative or descriptive study. Level VII. Opinion or consensus of authorities and/or expert committee/expert reports.

Literature research was conducted in the Virtual Health Library, in the Medline, SciELO, Lilacs and BDENF databases. Also, at the National Library of Medicine (NLM) through PubMed, CINAHL and SciVerse Scopus. The search in the databases was completed in March 2018, using the following mechanisms: PubMed and Cinahl: immunization [MeSH Terms] AND nursing [Title/Abstract]; Bireme: mh: immunization AND tw: nursing OR mh: vaccination AND tw: nursing; Scopus: KEY (immunization) AND ABS (nursing) OR KEY (vaccination) AND ABS (nursing).

The inclusion criteria were: papers in academic journals; abstract available in the databases and written in Portuguese, English or Spanish; a clear indication, in the abstract, of the theme regarding the practice of nursing in vaccination; complete text in English, Spanish or Portuguese; studies that answered the research question; published in the period from January 2010 to December 2017. We excluded studies that did not fulfill the criteria of the research, after evaluation of the quality and methodological rigor. Critical analysis was performed looking for explanations for different or conflicting results in the different studies. ${ }^{[10,11]}$

The practical dimensions of nursing in vaccination were: 1) Supervision/management: evaluation of vaccination indicators (coverage rates and abandonment rates); rapid coverage monitoring; educational actions; organization of vaccination campaigns. 2) Daily routine in vaccination: administration of immunobiological; registration of vaccination actions; daily production (quantitative doses of vaccines that were used, applied or disregarded, inventory, Post-Vaccination Adverse Events [PVAE]) notification and monthly consolidated; cold network (measures of temperature, ducts against changes in temperature); vaccination campaigns; missed vaccination opportunities.

For the collection of data, a synoptic table was elaborated contemplating the following variables: main author, reference number, periodical, year of publication, level of evidence, methodology employed and main findings (data not shown). ${ }^{[12]}$ A papers database was created with endNote software for screening papers. In addition, the studies underwent peer review to attest the reliability of the results, to guarantee the scientific rigor demanded in research of this nature.

\section{RESULTS}

Through the search strategies in the databases were found 1,399 papers, which addressed the issue of vaccination and nursing. After a critical reading of the abstracts and refine- 
ment of the search using the selection criteria, 79 papers were the final sample (see Figure 1).

full read for critical analysis, 49 were selected, composing

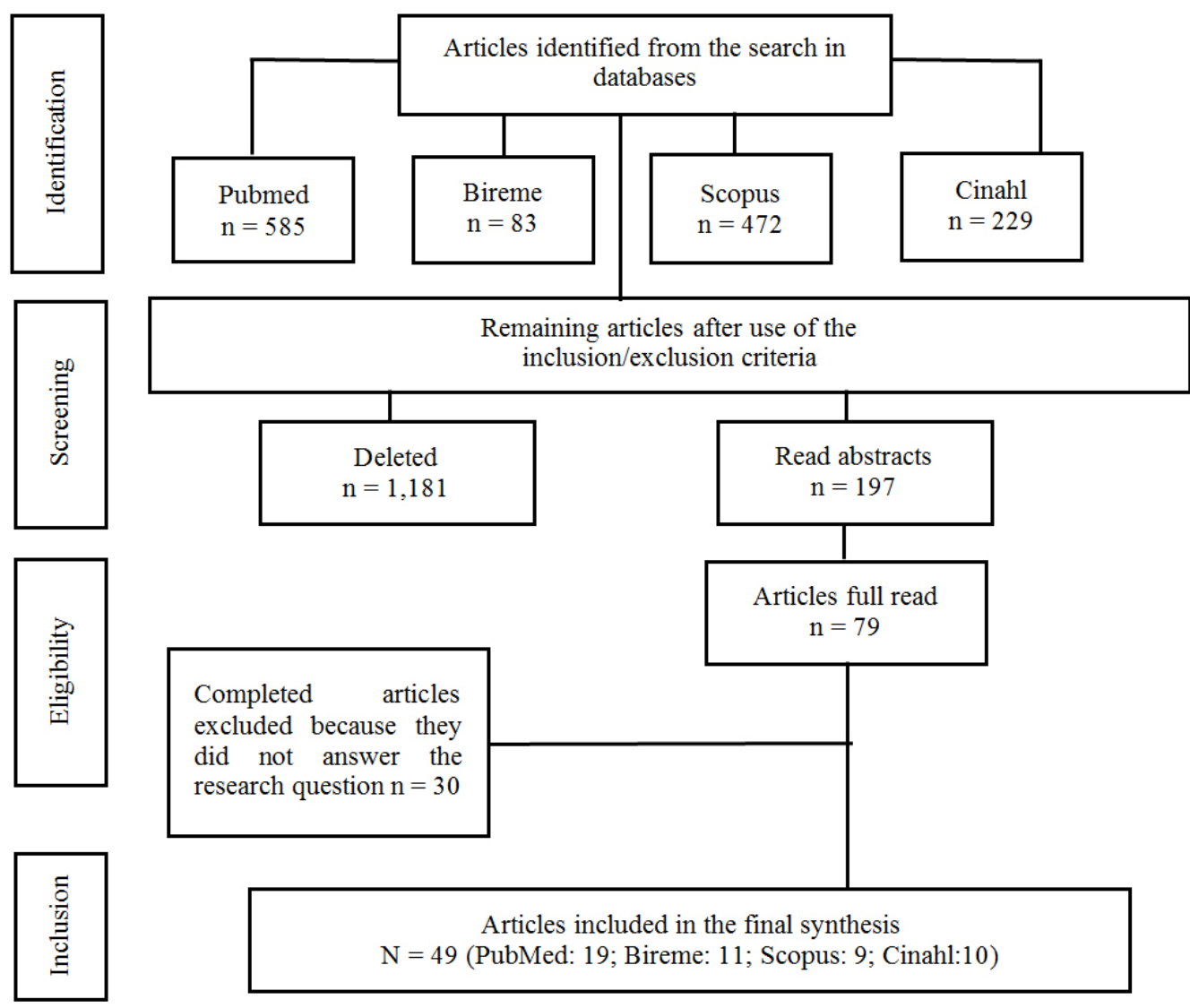

Figure 1. Flowchart with the distribution of papers located, excluded and selected, according to the databases. Campinas, SP, Brazil, 2018

Figure 2 shows the degree of scientific recommenda- fied with randomization, ${ }^{[19,34,56,57]}$ level III, represented the tion of the studies included in the review. ${ }^{[9]}$ Most of the a papers $(73.47 \%, 36 / 49)$ were classified with level of evidence VI, with mainly descriptive studies. ${ }^{[13-18,20-33,35,37,38,43,44,46-52,55,58-60]}$ The studies identi-

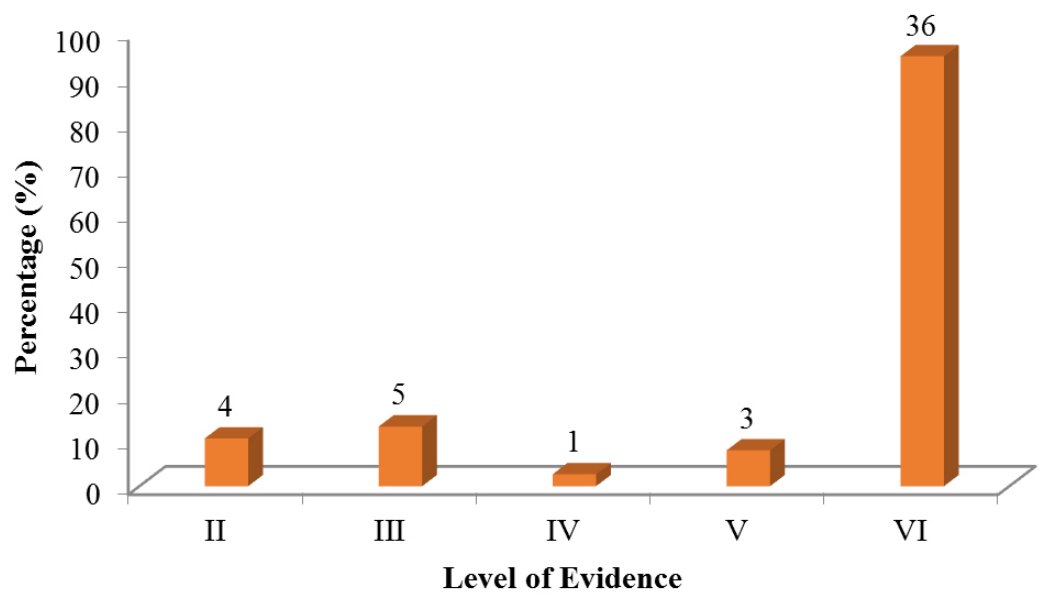

Figure 2. Distribution of articles on nursing practices in vaccination, according to the level of evidence, 2018 
The publications were grouped according to similarity crite- $(14.28 \%, 7 / 49)$, (iv) management/supervision $(14.28 \%, 7 / 49)$ ria into four categories: (i) vaccine coverage $(42.86 \%, 21 / 49)$, (see Figure 3).

(ii) vaccine administration $(28.58 \%, 14 / 49)$, (iii) vaccination

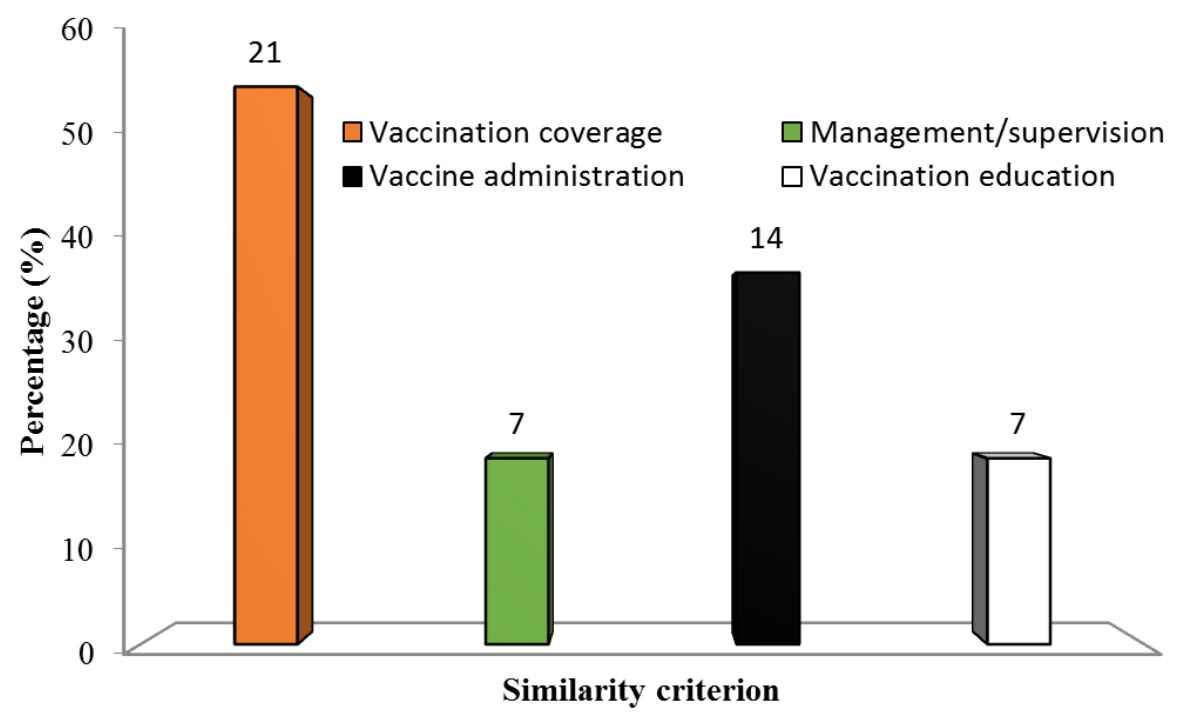

Figure 3. Categorization of studies of nursing practices in vaccination, by thematic similarity criterion, 2018

\subsection{Vaccination coverage}

Almost half of the papers found $42.86 \%$ were grouped in this thematic category. The papers cover, in the majority, contents directed to the vaccination coverage of some vaccine or vaccination coverage of the campaign of some vaccine. Influenza vaccine coverage was highlighted in several countries, with 10 papers (20.41\%) addressing this issue, researching the influenza vaccination coverage of health workers from long-stay institutions, ${ }^{[20,21,26,29]}$ from residents of long-stay institutions, ${ }^{[23,24,31]}$ hospitals $^{[14,19]}$ and nursing students. ${ }^{[18]}$

Hepatitis B vaccination coverage was present in three papers $(6.12 \%)$, analyzing the coverage by this vaccine among nursing professionals, ${ }^{[13]}$ on the general population of a Brazilian state ${ }^{[17,33]}$ for the respective age groups advocated by the national immunization program and to evaluate the impact of the vaccination rate, in relation to the obligation to vaccinate to enroll in educational institutions in each municipality. ${ }^{[28]}$ Vaccination against Human Papilloma Virus (HPV) with two papers $(4.08 \%)$ underscores the importance of carrying out vaccination in the school environment, increasing vaccination coverage ${ }^{[16]}$ and a study to identify the perception of health professionals about barriers and facilities for adherence of adolescents. ${ }^{[27]}$

Other papers addressed diverse strategies for analyzing or increasing vaccine coverage of some specific vaccines. As a study carried out in a state of Brazil, to analyze the morbidity due to acute gastroenteritis after the implantation of the rotavirus vaccine, ${ }^{[15]}$ compared to the period before its implan- tation. A study aimed at drawing a parallel between worker health and adult immunization, ${ }^{[22]}$ established the planning of several internal actions and partnerships with the public network, aiming to increase vaccination coverage in this specific population. Vaccination coverage against measles, rubella, mumps and pertussis ${ }^{[25]}$ was evaluated among hospital health professionals in Italy, also being part of occupational health.

Vaccination coverage against tetanus was evaluated in a rural population ${ }^{[30]}$ in Kentucky, United States of America (USA), specific actions were undertaken with this population to increase vaccination coverage. A study carried out in New Zealand has provided an example of the organization of an emergency program for vaccination against pneumococcus $C,{ }^{[32]}$ due to the outbreak of the disease, to achieve greater vaccination coverage in the shortest possible time and to control the spread of the disease.

\subsection{Vaccination management}

Our study had 14 papers (28.58\%) in this group. Of these, five papers $(35.71 \%)$ contemplated techniques/interventions aimed at reducing pain during the act of administering the immunobiological. The "cough trick" was used as a "distraction", at the exact moment when the immunobiological was to be administered, with an effective response in some children from four to five years and from 11 to 14 years old. ${ }^{[41]}$ A review of the literature has examined the use of breastfeeding, before, during and after the administration of the immunobiological, finding a decrease in pain during the 
procedure and similar efficacy to other interventions. ${ }^{[42]}$ In adolescents from 11 to 12 years old, the technique of "relaxation and imagination" was used to reduce pain during the HPV vaccine. ${ }^{[45]}$ It was not effective and was not indicated in the routine. The technique of music therapy ${ }^{[53]}$ was employed, reducing the suffering of the children, however, was not able to reduce the pain. Sucrose $30 \%{ }^{[54]}$ was able to reduce pain and soothe children under 15 months.

Seven other articles $(50 \%)$ in this group analyzed the question of PVAE, which is directly related to the administration of the vaccine. A study conducted in Brazil, with secondary data from the PVAE Information System from 1999 to 2008, allowed us to know the profile of PVAE in Brazil and showed that most of these events are related to nursing practice, ${ }^{[44]}$ denoting the need for investments aimed at raising awareness managers and nurses themselves, on the need to train human resources, with the implementation of continuing education in health services. A qualitative study with health professionals sought to identify the professionals' awareness and knowledge about how to act in the face of an PVAE. ${ }^{[46]}$ The authors have identified that the notification of the PVAE has been infrequent, there is a lack of knowledge of which events are to be reported, lack of professional training and many do not have the time or do not know how to use the PVAE notification system. Studies carried out in Scotland, Kenya and Brazil with health professionals and nursing students analyzed the knowledge and attitudes towards an PVAE. ${ }^{\text {47, 50-52] }}$ In a study carried out in the city of Vassouras, Rio de Janeiro, Brazil, he evaluated, among other things, the technique of immunobiological administration, with several errors in the process, such as dilution, needle use, bottle cleaning and lack of hand hygiene. ${ }^{[43]}$

\subsection{Vaccination education}

Although present in almost all papers, mentioning the need for better adaptation of this topic, both in the training of health professionals and in their continuing education, seven papers $(14.28 \%)$ addressed this issue directly. In a qualitative study conducted in Porto Alegre, Brazil, the education work by nursing professionals in the vaccination rooms was identified in the guidance on the vaccination of travelers, highlighting the interval between doses and vaccines to be received depending on the destination of the patients travelers. $^{[55]}$

An intervention held by seminars called "Flu 15", reached a change in the behavior of health professionals to receive influenza vaccination and improved their understanding of the importance of vaccination. ${ }^{[56]}$ Through a multidisciplinary intervention, with emphasis on educational actions, a quasiexperimental study was developed. ${ }^{[57]}$ In the group under intervention, there was an improvement in the vaccination rate, in relation to the control, suggesting the importance of permanent education both among the employees and among the residents of the therapeutic homes where the study was carried out. Similarly, the implementation of multifaceted interventions based on an ecological model increased significantly vaccination rates and healthcare providers absenteeism decreased. ${ }^{[61]}$

In Canada, a national study was carried out evaluating the content of the guidelines of the national curriculum for the training of health professionals on vaccination. ${ }^{[58]}$ They observed a great variation of workload dedicated to this theme, which reflects knowledge gaps among future professionals. Another study developed in an academic environment in Vietnam sought to evaluate the knowledge of health professionals about hepatitis B. ${ }^{[59]}$ More than half of the students were unaware of the disease and had not received the hepatitis B vaccine. In Finland, a study was carried out to evaluate the vaccination skills of public health nurses. ${ }^{[60]}$ The professionals were interested in receiving updates on the subject. Some gaps in knowledge have also been identified.

\subsection{Vaccine management/supervision}

The management/supervision in the routine of vaccination counted on seven papers $(14.28 \%)$. The focus of these papers are actions aimed at increasing the vaccination rate, evaluating the organizational structure and interprofessional integration, identifying possibilities and intervening factors in the vaccination process, among others. A study conducted in Melbourne, Australia, in tertiary hospitals, points out several strategies used to improve vaccination coverage among professionals. ${ }^{[34]}$ Similar strategies were implemented in Vermont/USA to increase vaccine coverage of nursing students. ${ }^{[39]}$ In Fortaleza, Ceará, Brazil, we sought to analyze the physical structure and daily practices of vaccination ward professionals and their interactions with other professionals in the family health team. ${ }^{[35]}$ In Minas Gerais, Brazil, the aim was to identify how daily practices in vaccination are given, such as supervision, knowledge and behaviors, human resources training and physical structure compliance. ${ }^{[38]}$ In a tertiary hospital in the USA, a protocol was implemented to increase the rate of pneumococcal vaccination. ${ }^{[36]}$ In the state of Pennsylvania, USA, actions were directed to nursing students in the second through fourth years, through the dissemination and awareness of students to increase vaccination coverage rates. ${ }^{[37]}$ A review of the literature has raised the existing bibliography during the period studied in order to list the factors that permeate the right to immunization in childhood and adolescence and the ethical issues surrounding vaccination. ${ }^{[40]}$ 


\section{Discussion}

The issue of vaccination is very diverse, comprehensive and widely covered in the scientific literature. In the databases researched and considering the inclusion and exclusion criteria, in the last five to seven years, we obtained 49 papers that dealt with the practice of nursing in vaccination. Most of the papers used as basic type of research the descriptive methodology, in which surveys and investigations of different types are carried out with the purpose of describing the characteristics of a certain population or phenomenon in a certain period, using standard techniques of collections of data, as a questionnaire and systematic observation. ${ }^{[62]}$

Vaccination coverage is a very relevant topic in the scientific literature on vaccination, representing 21 papers $(42.86 \%)$ of the final sample. Concern about achieving high vaccine coverage in the general population, reducing the risk of occupational diseases such as hepatitis B and influenza among health professionals and students in health care courses has been the subject of many studies. Vaccine coverage above $80 \%$ for some vaccines and above $95 \%$ for others is desired to achieve a higher level of protection against vaccine-preventable diseases. ${ }^{[63]}$ Vaccination among health professionals minimizes the risk of contracting occupational diseases, such as hepatitis $\mathrm{B}^{[13]}$ and influenza, ${ }^{[14,19,21]}$ which also reduces the risk of transmission of the latter, especially among the elderly, who have a weakened immune system. It also allowed the identification of barriers and facilities for the receipt of some vaccines and the knowledge of students and health professionals about immunopreventable diseases and the vaccines that prevent it. ${ }^{[14,16,18,20,26,30]}$

Regarding the influenza vaccine, there is concern that it may cause the disease and be ineffective in preventing influenza. ${ }^{[19]}$ Vaccination rates were low among health professionals and nursing students. ${ }^{[14,17,18,20,21,26,29]}$ The main reasons for the professionals to receive the flu vaccine is to protect themselves against the disease, follow the recommendations of the vaccination program and work medicine, free the vaccine, protect the health of family members and patients. ${ }^{[14,18,26]}$ While not receiving the vaccine, they cited the vaccine ineffectiveness, fear of adverse reactions, being healthy enough to prevent the flu, lack of time, possible absenteeism, the time the vaccine was released by the institution to be insufficient. ${ }^{[26]}$ This research, however, found high rates of vaccine coverage among nursing home residents. ${ }^{[20,23,24]}$

Many studies used the primary data generated in the vaccination campaigns/routine as a data source, ${ }^{[15,17,23,24,28,29,31,33,44]}$ showing the need to have a reliable public domain database that allows further anal-

Published by Sciedu Press ysis, as close to reality. These data allow estimating the percentage of vaccine-preventable diseases pre and postimplantation of vaccines ${ }^{[15,17]}$ or follow the evolution of vaccine coverage over time, ${ }^{[28]}$ after implantation of some intervention measure ${ }^{[16,22,28,30,32]}$ or data related to adverse reactions to vaccines. ${ }^{[33,44]}$

Management is historically present in the work of the nurse with qualified human resources and adequate organization of work. Be the means/instruments physical resources, financial resources, materials and administrative knowledge, either by planning, coordination, direction and control. ${ }^{[64]}$ In all analyzed papers there were to a lesser or greater degree characteristics of management/supervision, such as the organization of campaigns, ${ }^{[34]}$ follow-up of the vaccination process as a whole ${ }^{[35,38]}$ use of electronic tools to screen patients eligible for vaccines, ${ }^{[35]}$ identification of reasons why individuals accept or not receive a vaccine ${ }^{[37,39]}$ and to implement interventions that contribute with the increase in the vaccination rate. Accompaniment of vaccine coverage, implementation of programs to increase vaccine coverage are also part of the management and supervision process, even though it is listed in another grouping.

As with management/supervision, the issue of education related to vaccination was present in most studies. The need for permanent education and training of the professionals responsible for immunization ${ }^{[14,19-22,25,35,36,38,43,46,57,60,61]}$ of the mothers, ${ }^{[16,42]}$ of the users ${ }^{[17,55,57]}$ and of the students ${ }^{[18,56,58,59]}$ is critical to achieving vaccine coverage targets and maintaining reduced levels of immunoprevalent diseases. Through education, knowledge is made available to the target population and improved vaccine coverage, and is strongly recommended by scientific evidence to improve immunization coverage of children and adults in the general community and clinic-based settings in a variety of contexts and concomitant with other activities individually or collectively. ${ }^{[65]}$

Studies that sought to identify interventions to reduce pain during immunobiological administration ${ }^{[41,42,45,53,54]}$ may contribute to increased vaccine coverage and reduce stress, especially in children and when multiple doses are needed, which may contribute so that the parents do not take their children to vaccinate. Providing physical space, hand hygiene, dilution of immunobiologicals and proper administration of the vaccine contributes to the reduction of post-vaccinal adverse events and to the maintenance of the credibility of immunization programs. ${ }^{[44]}$ Another interesting topic in this subject is the correct and adequate notification of PVAE, ${ }^{[44,46-48,50-52]}$ which contributes to the improvement of immunobiological quality and to the identification of altered products that may 
cause harm, rather than the benefits expected from the receipt of vaccines.

\section{Conclusion}

Nursing is a profession that covers several areas of health care. Its work in public health is leadership and organization of actions, in addition to its practical action. Here we highlight the nursing practices aimed at vaccination. Whether performing these practices, whether as an individual or collective to be vaccinated, as a professional or student, organizing and evaluating vaccination actions. Concern about establishing high vaccine coverage was evident. Most of the papers found dealt with this issue, showing the need to have robust databases with reliable data. To have knowledge about how to calculate the vaccination coverage during training and as a professional, applying in the daily routine of its activities in vaccination rooms such a measure, to monitor, follow and intervene in different ways, to achieve the necessary goals, keeping rates of immunoprevalible diseases low.

Another important fact highlighted in the studies is the issue of training and continuing education about vaccination. The divergence in the training of health professionals, the variation of the workload, the gaps in knowledge, both in the training and among the professionals already graduated is evident. Few studies have directly addressed this issue, especially about education in vaccination of the population in general. A targeted population, with knowledge where to receive the vaccines, which vaccines to take, which diseases are prevented, possible adverse effects among others, would promote greater adherence to vaccination.

The issue of vaccination is a fertile field in the scientific production of nursing, so much so that in a period of seven years we find 49 papers discussing this important subject. The variety of themes and methodologies addressed in the papers analyzed and the diversity of levels of evidence make this wealth clear. However, it is observed that studies with a higher level of evidence on nursing practices in vaccination are timid. The methodology used here allowed the analysis and summarization of these papers with several approaches. However, there is still little production of clinical research and randomized clinical trials.

It is evident that vaccination goes far beyond the simple fact of administering an immunobiological, requiring an extensive and complex body of knowledge, with frequent updating of health professionals, especially nurses. Vaccination actions are effective in preventing diseases, and it is important to prioritize such actions in their daily practice. In nursing vaccination practices, nurses should assert their supervisor assignment, contributing to the organization of the service, continuing education of nursing staff, planning strategies to reach the goals of vaccination, evaluating vaccination coverage, working according to the population, through their education and awareness, and contribute with the body of knowledge about vaccination.

\section{Conflicts of Interest Disclosure}

The authors declare that there is no conflict of interest.

\section{REFERENCES}

[1] Lozano R, Naghavi M, Foreman K, et al. Global and regional mortality from 235 causes of death for 20 age groups in 1990 and 2010: A systematic analysis for the Global Burden of Disease Study 2010 Lancet. 2012 Dec; 380(9859): 2095-128.

[2] Plotkin SA, Plotkin SL. The development of vaccines: how the past led to the future. Nature Reviews Microbiology. 2011 Oct; 9(12): 88993. PMid:21963800 https://doi .org/10.1038/nrmicro2668

[3] Rappuoli R, Pizza M, Del Giudice G, et al. Vaccines, new opportunities for a new society. Proceedings of the National Academy of Sciences of the United States of America. 2014 Aug; 111(34): 12288-93.

[4] Organizacion Mundial de la Salud. Vacunas e inmunización: situación mundial. 3th ed. Ginebra: Organización Mundial de la Salud; 2010. 185 p.

[5] Savage C, Kub J. Public Health and Nursing: A Natural Partnership. International Journal of Environmental Research and Public Health. 2009 Nov; 6(11): 2843-8. PMid:20049229 https: //doi.org/10.3390/ijerph6112843

[6] Canadian Nurses Association. Nurses and Immunization - What You Need To Know! Nursing Now. Issues and Trends in Canadian
Nursing. 2001 Nov.

[7] Mendes KDS, Silveira RCCP, Galvão CM. Revisão integrativa: método de pesquisa para a incorporação de evidências na saúde e na enfermagem. Texto Contexto - Enfermagem. 2008 Dec; 17(4): 75864. https://doi.org/10.1590/S0104-07072008000400018

[8] Scott K, McSherry R. Evidence-based nursing: clarifying the concepts for nurses in practice. Journal of Clinical Nursing. 2009 Apr; 18(8): 1085-95. PMid:19077021 https://doi.org/10.1111/j . 1365-2702.2008.02588.x

[9] Stillwell SB, Fineout-Overholt E, Melnyk BM, et al. Evidence-based practice, step by step: searching for the evidence. The American Journal of Nursing. 2010 May; 110(5): 41-7.

[10] Beyea SC, Nicoll LH. Writing an integrative review. AORN Journal. 1998 Apr; 67(4): 877-80. https://doi.org/10.1016/S0001-2 092 (06) 62653-7

[11] Ganong LH. Integrative Reviews of nursing research. Research in Nursing \& health. 1987; 10(1): 1-11. https://doi.org/10.100 2/nur. 4770100103

[12] Ursi ES, Galvão CM. Prevenção de lesões de pele no perioperatório: revisão integrativa da literatura. Revista Latino-Americana de Enfer- 
magem. 2006; 14(1): 124-31. https://doi.org/10.1590/S010 4-11692006000100017

[13] Ganczak M, Ostrowski M, Szy chc Z, et al. A complete HBV vaccination coverage among Polish surgical nurses in the light of anti-HBc prevalence: A cross-sectional sero-prevalence study. Vaccine. 2010 May; 28(23): 3972-6.

[14] Sánchez-Payá J, Hernández-García I, Sañudo JB, et al. Determinantes de la vacunación antigripal en personal sanitario, temporada 2009-2010. Gaceta Sanitaria. 2011 Feb; 25(1): 29-34.

[15] Rissardo LK, Furlan MCR, Marcon SS, et al. Hospital morbidity before and after vaccination program against rotavirus in the state of Paraná-Brazil: exploratory - descriptive study. Online Brazilian Journal of Nursing. 2016 Mar; 9(2).

[16] McClure CA, Ma cSwain MA, Morrison H, et al. Human papillomavirus vaccine uptake in boys and girls in a school-based vaccine delivery program in Prince Edward Island, Canada. Vaccine. 2015 Apr; 33(15): 1786-90.

[17] Pudelco P, Koehler AE, Bisetto LHL. Impact of vaccination in the reduction of hepatitis B in Paraná. Revista Gaúcha de Enfermagem. 2014 Mar; 35(1): 78-86. PMid:24930276 https ://doi .org/10.1 $590 / 1983-1447.2014 .01 .37821$

[18] Koharchik LS, Salman K, Hardy E, et al. Influenza immunisation status among nursing students. Journal of Infection Prevention. 2012; 3(5): $174-8$.

[19] Seale H, Wang Q, Yang P, et al. Influenza vaccination amongst hospital health care workers in Beijing. Occupational Medicine. 2010 Aug; 60(5): 335-9.

[20] Vaux S, Noël D, Fonteneau L, et al. Influenza vaccination coverage of healthcare workers and residents and their determinants in nursing homes for elderly people in France: a cross-sectional survey. BMC Public Health. 2010 Mar; 10: 159. PMid:20338028 https://doi.org/10.1186/1471-2458-10-159

[21] Daugherty JD, Blake SC, Grosholz JM, et al. Influenza vaccination rates and beliefs about vaccination among nursing home employees. American Journal of Infection Control. 2015 Feb; 43(2): 100-6.

[22] Santos PR, Noronha NH, Mattos UAO, et al. Nursing and healthcare for workers: the experience of the immunization action at Fiocruz/Manguinhos. Ciência e Saúde Coletiva. 2011 Feb; 16(2): 553-65.

[23] Banach DB, Ornstein K, Factor SH, et al. Seasonal Influenza Vaccination among Homebound Elderly Receiving Home-Based Primary Care in New York City. Journal of Community Health. 2012 Feb; 37(1): 10-4.

[24] Shah SM, Carey IM, Harris T, et al. The impact of dementia on influenza vaccination uptake in community and care home residents. Age and Ageing. 2012 Jan; 41(1): 64-9.

[25] Taddei C, Ceccherini V, Niccolai G, et al. Attitude toward immunization and risk perception of measles, rubella, mumps, varicella, and pertussis in health care workers working in 6 hospitals of Florence, Italy 2011. Human Vaccines \& Immunotherapeutics. 2014; 10(9): 2612-22. PMid:25483489 https : //doi .org/10.4161/21 645515.2014 .970879

[26] Gavazzi G, Filali-Zegzouti Y, Guyon AC, et al. French healthcare workers in geriatric healthcare settings staunchly opposed to influenza vaccination: The VESTA study. Vaccine. 2011 Feb; 29(8): 1611-6.

[27] Head KJ, Vanderpool RC, Mills LA. Health Care Providers' Perspectives on Low HPV Vaccine Uptake and Adherence in Appalachian Kentucky. Public Health Nursing. 2013 Jul; 30(4): 351-60. PMid:23808860 https://doi .org/10.1111/phn.12044

[28] Furlan MCR, Rissardo LK, Oliveira RG, et al. Impact of the compulsory school vaccination against hepatitis B in adolescents: exploratory-descriptive study. Online Brazilian Journal of Nursing. 2010; 9(2).

[29] Groenewold M, Baron S, Tak S, et al. Influenza Vaccination Coverage Among US Nursing Home Nursing Assistants: The Role of Working Conditions. Journal of the American Medical Directors Association. 2012 Jan; 13(1): e17-23.

[30] Main ME, Jones MS. Linking Community Partners to Increase Tetanus Immunizations Among Farmers. Workplace Health \& Safety. 2014 Nov; 62(11): 476-81.

[31] Li Y, Mukamel DB. Racial Disparities in Receipt of Influenza and Pneumococcus Vaccinations Among US Nursing-Home Residents. American Journal of Public Health. 2010 Apr; 100(S1): S256-62. PMid:20147674 https://doi.org/10.2105/AJPH. 2009.1734 68

[32] Mills C, Penney L. The Northland Emergency Meningococcal C Vaccination Programme. Australian and New Zealand Journal of Medicine. 2013 Apr; 126(1373): 30-9.

[33] Nora TTD, Paz AA, Linch GFC, et al. Situation of immunobiological vaccine coverage in the period from 2009-2014. Revista de enfermagem da UFSM. 2016 Oct/Dec; 6(4): 482-93.

[34] Heinrich-Morrison K, McLellan S, McGinnes U, et al. An effective strategy for influenza vaccination of healthcare workers in Australia: experience at a large health service without a mandatory policy. BMC Infectious Diseases. 2015 Feb; 15: 42.

[35] Luna GLM, Vieira LJES, Souza PF, et al. Aspects related to vaccine management and preservation in healthcare centers in the Northeastern Brazil. Ciência e Saúde Coletiva. 2011 Feb; 16(2): 513-521.

[36] Smith JG, Metzger NL. Evaluation of Pneumococcal Vaccination Rates After Vaccine Protocol Changes and Nurse Education in a Tertiary Care Teaching Hospital. Journal of Managed Care Pharmacy. 2011 Nov; 17(9): 701-8. PMid:22050395 https://doi .org/10.1 8553/jmcp. 2011.17.9.701

[37] Koharchik LS, Hardy E, Salman K. Evidence-based initiative to improve influenza immunization participation among undergraduate nursing students. Journal of Infection Preventio. 2012 Nov; 13(6): 186-91. https://doi.org/10.1177/1757177412462494

[38] Oliveira VC, Gallardo MOS, Cavalcante RB, et al. Weaknesses of vaccine storage in Primary Healthcare Centers. Revista Brasileira de Enfermamgem. 2015 Apr; 68(2): 291-6.

[39] Davis WS, Vami SE, Barry SE, et al. Increasing Immunization Compliance by Reducing Provisional Admittance. The Journal of School Nursing. 2016 Aug; 32(4): 246-57. PMid:26699951 https : //doi.org/10.1177/1059840515622528

[40] Bejo Wolkers PC, Silva SJ, Sayuri YM, et al. O direito à imunização na infância e adolescência: uma revisão narrativa. Ciencia y enfermería. 2016 Sep; 22(3): 85-96.

[41] Wallace DP, Allen KD, Lacroix AE, et al. The "Cough Trick:" A Brief Strategy to Manage Pediatric Pain From Immunization Injections. Pediatrics. 2010 Feb; 125(2): e367-73.

[42] Tansky C, Lindberg CE. Breastfeeding as a Pain Intervention When Immunizing Infants. The Journal for Nurse Practitioners. $2010 \mathrm{Apr}$; 6(4): 287-95. https://doi.org/10.1016/j.nurpra.2009.09 .014

[43] Silva TASM, Carreiro MA. Situational diagnosis of preparation and administration of immunobiologics. Revista Enfermagem UERJ. 2012 Oct/Dez; 20(4): 451-6.

[44] Bisetto LHL, Cubas MR, Malucelli A. Nursing practice in view of adverse events following vaccination. Revista da Escola de Enfermagem da USP. 2011 Oct; 45(5): 1128-34. PMid:22031373

[45] Nilsson S, Forsner M, Finnström B, et al. Relaxation and guided imagery do not reduce stress, pain and unpleasantness for 11-to 12- 
year-old girls during vaccinations. Acta Paediatrica. $2015 \mathrm{Jul}$; 104(7): 724-9.

[46] Parrella A, Braunack-Mayer A, Gold M, et al. Healthcare providers' knowledge, experience and challenges of reporting adverse events following immunisation: a qualitative study. BMC Health Services Research. 2013.

[47] Pulford A, Malcolm W. Knowledge and attitudes to reporting adverse drug reactions. British Journal of Nursing. 2010 Aug; 19(14): 899904. https://doi.org/10.12968/bjon.2010.19.14.49048

[48] Linheira-Bisetto LH, Ciosak SI, Cordeiro TLR, et al. Adverse events following immunization of the elderly. Cogitare Enfermagem. 2016 Oct/dec; 21(4): 01-10.

[49] Halcomb E, Hickman L. Attitudes and immunisation practices of Australian general practice nurses. Contemporary Nurse. 2016 Aug; 52(4): 440-6. https://doi.org/10.1080/10376178.2016.12 16754

[50] Oliveira ESA, Casarin ST, Ceolin T, et al. Care provided by the nursing team in care of post-vaccination adverse events. Revista de Enfermagem da UFPI. 2016 Abr-Jun; 5(2): 32-40. https : //doi.org/10.26694/reufpi.v5i2.5275

[51] Menor GSS, Costa DB, Olivindo DDF, et al. Adverse events after vaccination in children and nursing performance: an integrative review. Revista de Enfermagem da UFPI. 2016 Jan-Mar; 5(1): 89-95. https://doi.org/10.26694/reufpi.v5i1.2949

[52] Masika CW, Atieli H, Were T. Knowledge, Perceptions, and Practice of Nurses on Surveillance of Adverse Events following Childhood Immunization in Nairobi, Kenya. BioMed Research International. 2016.

[53] Yinger OS. Music Therapy as Procedural Support for Young Children Undergoing Immunizations: A Randomized Controlled Study. Journal of Music Therapy. 2016; 53(4): 336-63. https : //doi.or $\mathrm{g} / 10.1093 / \mathrm{jmt} / \mathrm{thw010}$

[54] Despriee ÅW, Langeland E. The effect of sucrose as pain relief/comfort during immunisation of 15-month-old children in health care centres: a randomised controlled trial. Journal of Clinical Nursing. 2016 Feb; 25(3-4): 372-80. PMid:26818364 https : //doi.or g/10.1111/jocn. 13057

[55] Mallet AP, Dall'agno CM, Souza DB. Yellow fever: nurse counseling on travelers' health at basic health clinics. Revista Gaúcha de Enfermagem. 2010 Jun; 31(2): 293-299. PMid:21500509
[56] Butteri MJ, Radu C, Huq F, et al. Flu in 15: A Novel 15-Minute Education Program to Promote Acceptance of the Influenza Vaccine Among Health Care Workers. Journal of the American Medical Directors Association. 2010 Sep; 11(7): 523-7.

[57] Hutt E, Radcliff TA, Oman KS, et al. Impact of NHAP guideline implementation intervention on staff and resident vaccination rates. Journal of the American Medical Directors Association. 2010 Jun; 11(5): 365-70. PMid:20511104 https ://doi.org/10.1016/j . jamda. 2009.09.017

[58] Pelly LP, MacDougallDMP, Halperin BA, et al. THE VAXED PROJECT: An Assessment of Immunization Education in Canadian Health Professional Programs. BMC Medical Education. 2010 Nov; 10: 86 .

[59] Pathoumthong K, Khampanisong P, Quet F, et al. Vaccination status, knowledge and awareness towards hepatitis Bamong students of health professions in Vientiane, Lao PDR. Vaccine. 2014 Sep; 32(39): 4993-9.

[60] Nikula A, Nohynek H, Puukka P, et al. Vaccination Competence of Public Health Nurses. Public Health Nursing. 2011 Nov/Dec; 28(6): 533-42.

[61] Ofstead CL, Amelang MR, Wetzler HP, et al. Moving the needle on nursing staff influenza vaccination in long-term care: Results of an evidence-based intervention. Vaccine. 2017 Apr; 35(18): 2390-5. https://doi.org/10.1016/j.vaccine.2017.03.041

[62] World Health Organization. Health Research Methodology: A guide for training in research methods. 2th ed. Manina: WHO; 2001. 237 p.

[63] Ministerio de Salud Pública. Programa Ampliado de Inmunizaciones. Ecuador: OPS/OMS; 2005. 128 p.

[64] Peres AM, Ciampone MHT. Management and general nursing competencies. Texto \& Contexto - Enfermagem. 2006 Jul/Sep; 15(3): 492-9.

[65] Task Force on Community Preventive Services. Recommendations Regarding Interventions to Improve Vaccination Coverage in Children, Adolescents, and Adults. American Journal of Preventive Medicine. 2000 Jan; 18(1S): 92-6. https ://doi.org/10.1016/ S0749-3797 (99) 00121-X 